\title{
Comparison of a Single Branch and a Double Branch R-C Models for the Li-ion Batteries Considering the Electric Vehicle Applications
}

\author{
SachinVrajlal Rajani ${ }^{1}$, Vivek J Pandya ${ }^{2}$ \\ Department of Electrical Engineering, V.V.P. Engineering College, Rajkot, Gujarat, India ${ }^{l}$ \\ Department of Electrical Engineering, PanditDeendayal Petroleum University, Gandhinagar, Gujarat, India ${ }^{2}$ \\ Email: sachin_3542@rediffmail.com ${ }^{1}$
}

\begin{abstract}
This paper explores the idea of comparing the single and double branch $\mathrm{R}-\mathrm{C}$ models for the Li-ion batteries considering the Electric Vehicle (EV) applications. The running range and the charging/discharging time are the utmost factors to be considered while designing the batteries for these applications. The Li-ion batteries are the common choice and the proven technology since many years for the EV and HEV applications and hence, to be modeled with the due consideration given to the Resistance (R), Capacitance (C), State of the Charge (SoC), Thermal Dependence of R and SoC. This paper covers all these parameters and their comparison for the single and double branch performance for the Li-ion batteries. The simulations are carried out in the MATLAB/Simulation ${ }^{\circledR}$ environment. The results showing comparison of the two models are also presented in the paper.
\end{abstract}

Index Terms-Li-ion Battery; Electric Vehicles (EVs); Modeling; R-C Branch

\section{INTRODUCTION}

The Hybrid Electric Vehicles (HEVs) started their journey in the late nineteenth century and that evolution process is still going on. With the growing concerns for the carbon footprints and issues of global warming, the scientists and researchers around the world are looking in depth for the technologies for transportation around the globe [1-3]. Their basic concentration is for the non-fossil fuel vehicles and the obvious choice is the Electric Vehicles (EVs) and the Hybrid Electric Vehicles (HEVs). There are few combinations like, (1) FHEV (Full Hybrid Electric Vehicle) - These vehicles have electric motors and internal combustion engines (ICE) working together and are suitable for the short distance when running on the electric power only. (2) BEV - known as the battery electric vehicles and powered by the energy stored in the battery. The batteries can be recharged from the grid. The main concentration of research in this area is the power density and the energy density enhancement and the longer distance to run for the BEVs. (3) FCEV (fuel cell electric vehicle) - it typically uses hydrogen to generate electricity and powers an electric motor. (4) EREV - known as the extended range electric vehicle. It consists of an internal combustion engine, on-board charger and an electric motor. It has a longer range than a battery vehicle [4-6].

Now, for the above mentioned EVs and HEVs the primary component is the battery and the Lithium Ion (Li-ion) batteries are the established batteries in this technological segment. Therefore, a mathematical model that shows the performance of these batteries considering the thermal dependence is utmost necessary. Over the past few years, researchers have come up with the various models of Li-ion batteries and the single branch $\mathrm{R}-\mathrm{C}$ and double branch $\mathrm{R}-\mathrm{C}$ models are the two main models. Here, in this paper, an attempt is made to compare these models considering the thermal effects, the battery parameters and the load effects. The batteries for these models are tested in the Simulink ${ }^{\circledR}$ environment of MATLAB $^{\circledR}$. The results 


\section{International Journal of Research in Advent Technology, Vol.7, No.5, May 2019 E-ISSN: 2321-9637 \\ Available online at www.ijrat.org}

proved are indicating the performance and the comparison of the models taken into consideration.

\section{MODEL FORMULATION}

As pointed out earlier, the basic models consist of either one RC or two RC branches. Both these models are shown in Figures 1 and 2 respectively. In both theseR-C models, the voltage source is shown by $\mathrm{E}$ and there is a definite relation between an open circuit voltage $\mathrm{E}$ and the State of Charge (SoC) of a battery. This relation is considered in the form of a look-up table in the MATLAB/Simulink ${ }^{\circledR}$ environment. Figure 3 shows the theoretical model of the Li-ion battery. This model has ' $n$ ' numbers of the branches where ' $n$ ' is an integer and its choice depends upon the required information from the model and complexity of the model. The components $\mathrm{R}-$ Resistance and CCapacitance show the internal opposition and a charge storage mechanism. In a single branch $\mathrm{R}-\mathrm{C}$ model, the $\mathrm{R}-\mathrm{C}$ effect is considered as the lumped parameters whereas, the two R-C branch model has two such lumped groups. These models show the dynamics of the battery pack. The further increment in the numbers of branches is always possible leading to the theoretical model of ' $n$ ' branches, where ' $n$ ' can be any integer but again as the numbers of branches are increased, the model complexity and the computational efforts are also increased. The State of Charge (SoC) has also a relation with the temperature $\mathrm{T}$. This correlation is also established by a look-up table.

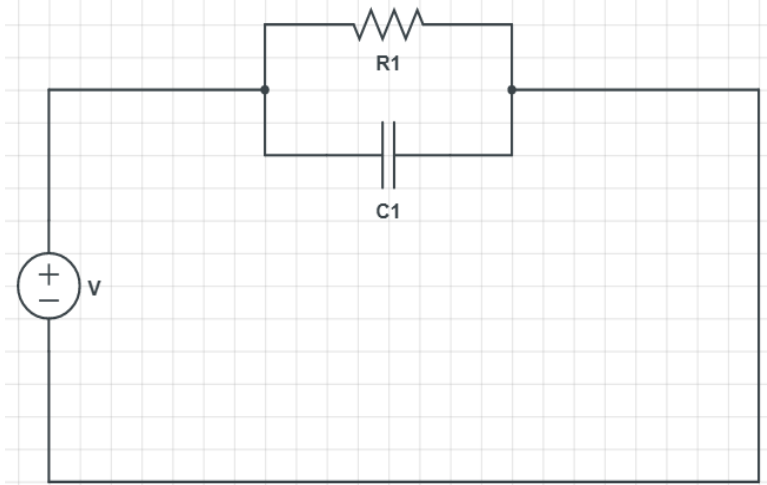

Figure 1. A Single Branch R-C Model of an Li-ion Battery

These all look-up tables are useful while plotting the charge/discharge characteristics, SoC and voltage profile for both the said models. For all the standard equation related to these models refer [7-8]. Here, the focusing point is comparison of the said models and not the theory or the equations associated with these models. One more resistance, $\mathrm{R}_{\mathrm{s}}$, that works as the internal series resistance can be shown connected in the series after the voltage source but it is not shown in these models.

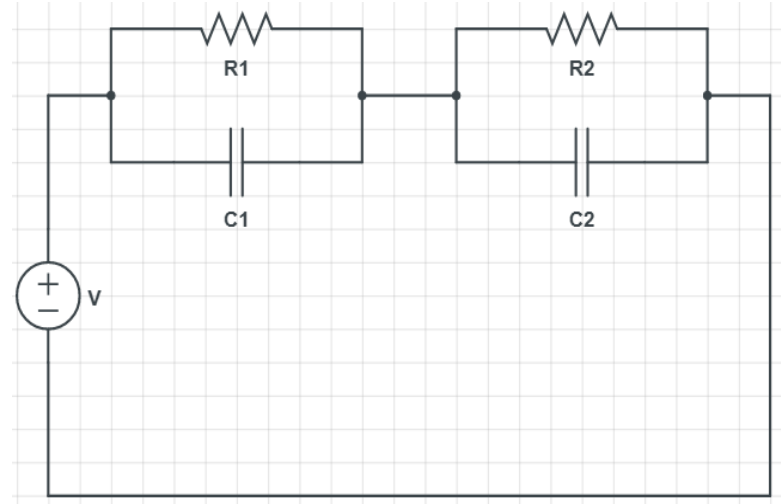

Figure 2. A Double Branch R-C Model of an Li-ion Battery

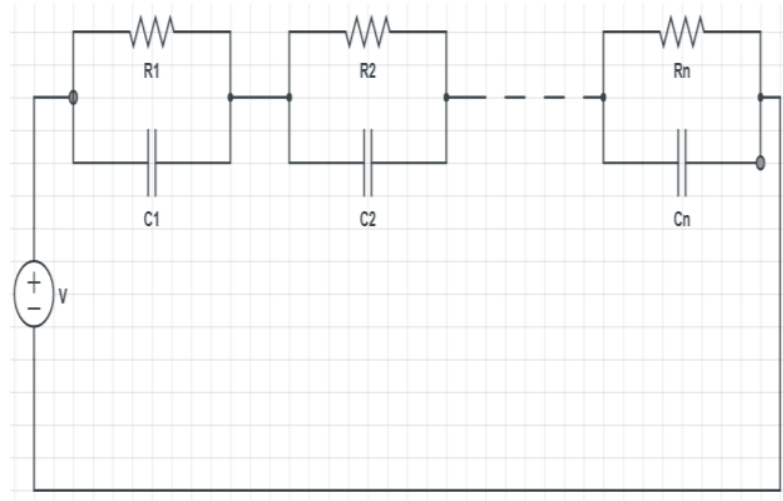

Figure 3. A Theoretical 'n' Branch R-C Model of an Liion Battery

\section{RESULTS AND DISCUSSION}

The single and double branch models of the Li-ion batteries were simulated in the Simulink ${ }^{\circledR}$ environment of MATLAB ${ }^{\circledR}$ and the results are presented below.

\subsection{Single Brach R-C Model}

Results for the single branch R-C model are shown in the figures 4 (a) to 4(d). Figure 4(a) shows the Charging/Load Current for the Single Branch R-C Model. Initially the charging current shoots up to value 


\section{International Journal of Research in Advent Technology, Vol.7, No.5, May 2019 E-ISSN: 2321-9637 \\ Available online at www.ijrat.org}

nearly to $31 \mathrm{~A}$ and then the numbers of discharge pulses are marked at the regular intervals of 3600 seconds that equals to one hour. Figure 4(b) shows the voltage profile for the single branch R-C model. It is clear from the figure that in the initial current charging period, the voltage profile also goes high and at the discharging currents at the prescribed intervals, the voltage touches to $1.95 \mathrm{~V}$ from initial value of $3.6 \mathrm{~V}$.

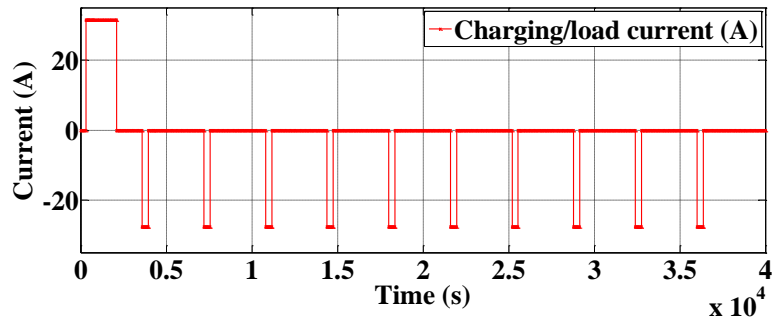

Figure 4(a) Charging/Load Current for the Single Branch R-C Model

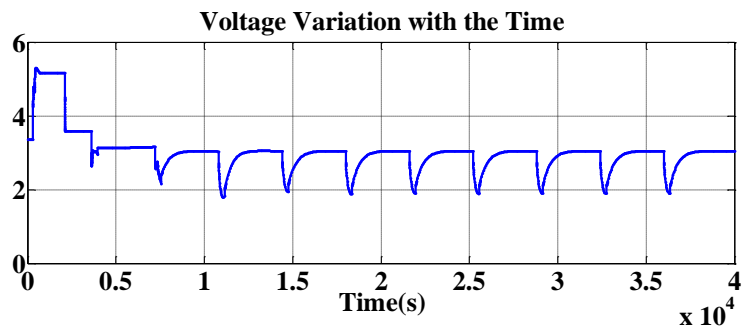

Figure 4(b) Voltage Profile for the Single Branch R-C Model

Figure 4 (c) presents the State of Charge $(\mathrm{SoC})$ for the Single Branch R-C Model. From the initial SoC of the battery let say $100 \%$, the SoC falls down by around $6 \%$ over the total simulation time of 36000 seconds or 10 hours. Again the pulses of $\mathrm{SoC}$ decrement are registered at the regular intervals correspond to the load current pulses. Figure 4(d) shows the temperature variation. Apart from the initial phase of charging, the temperature hovers between 20degree cen. to 37 degree cen. depending upon the successive load current pulses.

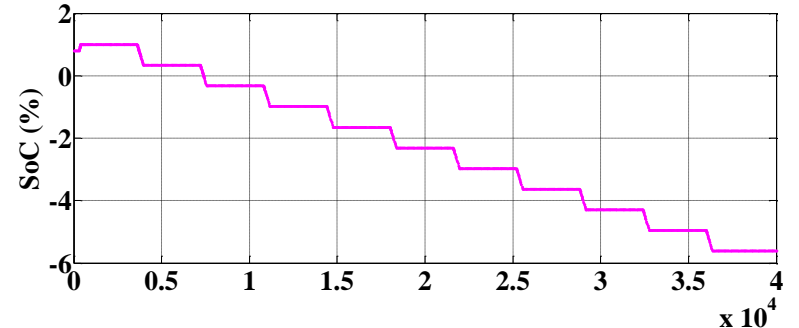

Figure 4 (c) State of Charge (SoC) for the Single Branch R-C Model

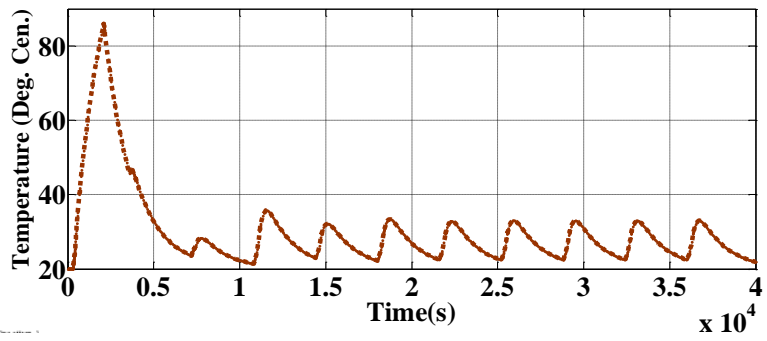

Figure 4 (d) Temperature Variation for the Single Branch R-C Model

\subsection{Double Brach R-C Model}

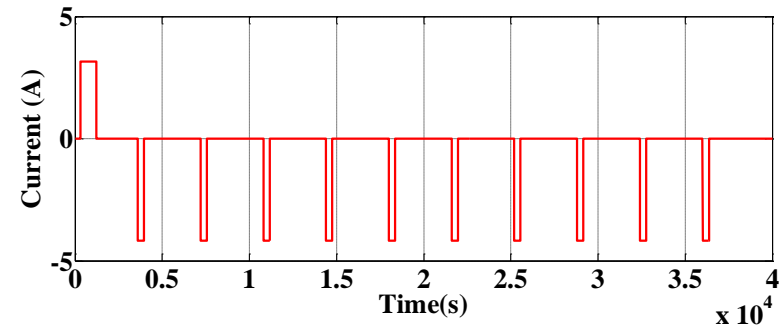

Figure 5(a) Charging/Load Current for the Double Branch R-C Model Volatge Variation with the Time (V)

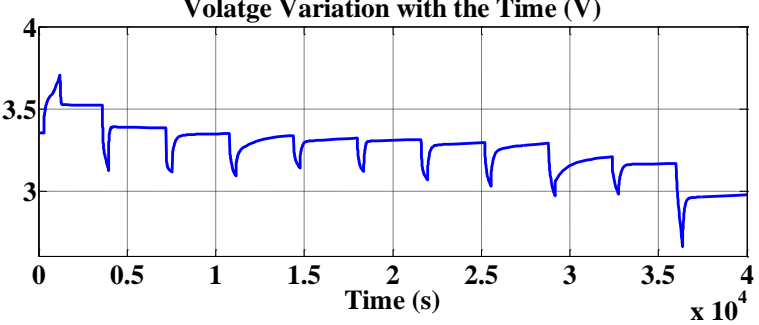

Figure 5(b) Voltage Profile for the Double Branch R-C Model

Similarly, Figures 5(a) to 5(d) shows the current variation, voltage variation, $\mathrm{SoC}$ variation and the temperature variation respectively for the Li-ion battery's double branch R-C model. Here, the discharging current was kept to $4 \mathrm{~A}$ at the regular intervals of 3600 seconds or 1 hour. The voltage profile 


\section{International Journal of Research in Advent Technology, Vol.7, No.5, May 2019 E-ISSN: 2321-9637 \\ Available online at www.ijrat.org}

has spikes from $3.4 \mathrm{~V}$ to $3.1 \mathrm{~V}$ in the discharging mode. In comparison to the single branch model, the spikes in the voltage profile are sharp basically due to fast charging process of the first branch and the charge redistribution process. The SoC variation is has nearly the same pattern as of the single branch $\mathrm{R}-\mathrm{C}$ model but the temperature variation has many transients in comparison to the single branch R-C model.

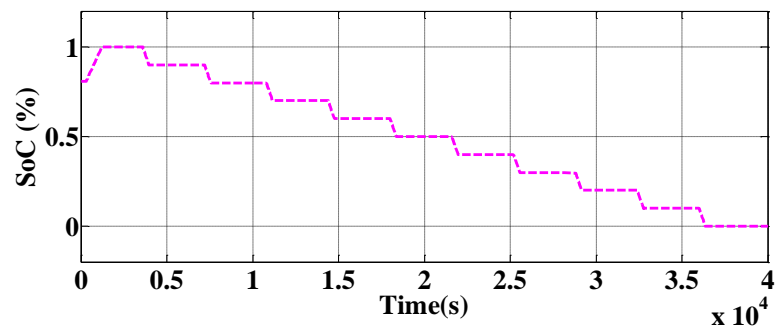

Figure 5(c) State of Charge (SoC) for the Double Branch R-C Model

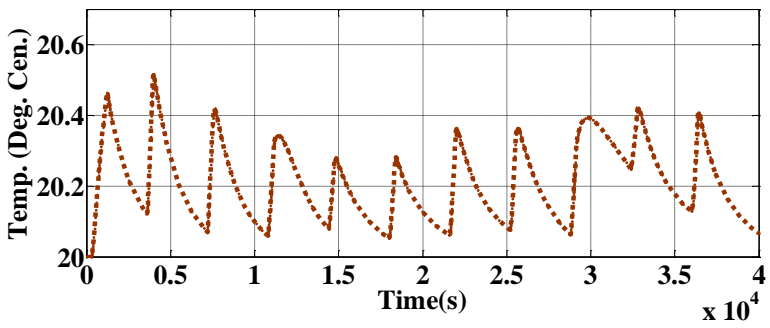

Figure 5(d) Temperature Variation for the Double Branch R-C Model

\section{CONCLUSION}

After formulating the single and the double branch model for the Li-ion battery, both these models were compared for the voltage profile variation, State of the Charge variation and the temperature variation. One of the important point to note is in the variation of the voltage profile. For the single branch $\mathrm{R}-\mathrm{C}$ model, the voltage variation is without much of the spikes but the double branch R-C model has many transients. The simple reason behind this is for the second order circuit like the double branch model, the charge redistribution process and fast charging process of the first branch. The SoC variation for the both these models is almost same but again the temperature variation graph for the double branch model is with transients basically due to response of the second order R-C branch.

\section{ACKNOWLEDGEMENTS}

This work is sponsored by Gujarat Council on Science and Technology (GUJCOST), Gandhinagar, India, a Gujarat state body to fund the science and technology research work. The Reference No. of the Grant is GUJCOST/MRP/2015-16/1116. This work is also supported by V.V.P. Engineering College, Rajkot, Gujarat, India.

\section{REFERENCES}

[1] Sachin Rajani; Pandya Vivek J; Chirag Vibhakar, et al (2018). Supercapacitor-Battery Hybridization to Prevent Battery Life for Pulsed Load Applications. Journal of Power Electronics \& Power Systems (JoPEPS).; 8(1): $1-15 \mathrm{p}$.

[2] Renuka R; John Fredrick V; Saravanan S, et al (2001). 3,3'-Dinitrobenzophenone as a Cathode Material in a Magnesium/Zinc Based Primary Battery. Indian J Chem A.; 40: 175-181p.

[3] Das SS; Srivastava Pankaj Kumar; Singh NP, et al (2010), Preparation of Some Metal Chloride Doped Silver Phosphate Glass Electrolytes: Application to Solid State Batteries. Indian J Eng Mater Sci. 17: 123130p.

[4] Singh Ram Adhar; Rao OS; Singh VK (1996). Rechargeable Iodine Batteries Based on Charge Transfer Materials Having Mixed Conduction. Indian J Eng Mater Sci. 3: 23$30 \mathrm{p}$.

[5] Sachin Vrajlal Rajani; Pandya Vivek (2016), J. Experimental Verification of the Rate of Charge Improvement Using Photovoltaic MPPT Hardware for the Battery and Ultracapacitor Storage Devices. Sol Energy. 139: 142-148p.

[6] Junvi Shen; Alireza Khaligh (2015), A Supervisory Energy Management Control Strategy in a Battery/Ultracapacitor Hybrid 
International Journal of Research in Advent Technology, Vol.7, No.5, May 2019

E-ISSN: 2321-9637

Available online at www.ijrat.org

Energy Storage System. IEEE Trans Transport

Electrific. 2015; 1(3): 223-231p.

[7] Guannan He; Oixin Chen; Chongqing Kang et al(2016), Optimal Bidding Strategy of Battery Storage in Power Markets Considering Performance-Based Regulation and Battery Cycle Life. IEEE Trans Smart Grid. 7(5): 2359-2367p.

[8] Amir Ostadi, Mehrdad Kazerani (2015), A Comparative Analysis of Optimal Sizing of Battery-Only, Ultracapacitor-Only, and Battery-Ultracapacitor Hybrid Energy Storage Systems for a City Bus. IEEE Trans Veh Technol. 64(10): 4449-4460p. 